\title{
A novel integrated platform for the identification of surgical margins in oral squamous cell carcinoma: results from a prospective single-institution series
}

Alessandro Baj ${ }^{1,2+}$, Nicola Fusco ${ }^{1,3+}$, Alessandro Bolzoni ${ }^{1,2}$, Daniela Carioli ${ }^{4}$, Camilla Mazzucato ${ }^{2}$, Alice Faversani ${ }^{1,3}$, Lorenzo Bresciani ${ }^{2}$, Marco Maggioni ${ }^{3}$ and Pasquale Capaccio ${ }^{1,4^{*}}$

\begin{abstract}
Background: The optimal surgical margins assessment is capital in oral squamous cell carcinoma (OSCC) management. We evaluated the clinical benefits of integrating intraoperative macroscopic margin (MM) assessment and narrow band imaging (NBI).

Methods: Sixteen OSCC patients eligible for surgery were prospectively enrolled. For each patient, 2 to 6 bioptic samples of MM and NBI margins were obtained and histologically analyzed for the presence of dysplasia and lymphocytes. Microvessel density was investigated by CD34 immunohistochemistry.

Results: Taken together, 104 specimens were analyzed, including 15\% tumors, 33\% MM, 33\% NBI margins, and 19\% MM-NBI overlapping margins. The NBI margins were closer to the lesion in 50\% cases, while the same number of MM were more conservative than NBI, irrespective of the tumor site. The rate of histologically positive margins was similar among the two methods, akin to the microvessel density.
\end{abstract}

Conclusions: MM assessment should be integrated but not replaced with the NBI technology to allow for more conservative surgery.

Keywords: Oral squamous cell carcinoma, NBI, Narrow band imaging, Microvascular density, Surgical margins

\section{Background}

Oral squamous cell carcinoma (OSCC) is the most frequent histological type of head and neck cancer and one of the most prevalent malignant neoplasms worldwide [1]. Despite the recent achievements in the diagnosis and treatment of these patients, OSCC is showing increasingly high recurrence rates $[2,3]$. Due to its clinical and biological complexity, therapeutic decision-making is not an easy task, even in multidisciplinary settings. Anatomical site, clinical stage, and pathological features

\footnotetext{
* Correspondence: pasquale.capaccio@unimi.it

${ }^{+}$Alessandro Baj and Nicola Fusco contributed equally to this work.

'Department of Biomedical, Surgical, and Dental Sciences, University of Milan, Fondazione IRCCS Ca' Granda Policlinico, via Francesco Sforza, 35, 20122 Milan, Italy

${ }^{4}$ Otolaryngology Unit, Fondazione IRCCS Ca' Granda Ospedale Maggiore Policlinico, Milan, Italy

Full list of author information is available at the end of the article
}

of the primary tumor are the foremost elements to guide OSCC treatment, which remains surgically-based either in single or in combined therapeutic settings [4]. During surgical removal, the visible neoplastic area should be resected with a threshold of normal tissue, whose edge represents the mucosal margin [5]. To improve patient's outcome, the surgical radicality (i.e. histologically-proved negativity of the mucosal margin) is fundamental [6]. Indeed, there are multiple lines of evidence to suggest that failure to reach clear margins in OSCC is related to an increased risk of local recurrence and, subsequently, reduced chances of survival. However, there are no widely adopted guidelines for pre- and intra-operative margins identification. To date, finding the "golden strategy" for the optimal assessment of the surgical margins remains one of the most critical issues in OSCC management $[7,8]$. 
Several approaches have been proposed to enhance the traditional white-light macroscopic margins (MM) identification in OSCC. Among them, the Narrow Band Imaging (NBI) technology have shown good performance and is currently employed in several Centers [9, 10]. This augmented reality tool increases the contrast between the epithelial surface and the subjacent vascular network, allowing for the visualization of the mucosal and submucosal (micro) vascular patterns. The principle by which NBI can be employed for surgical margin assessment is based on the evidence that neoangiogenesis is a crucial step in tumor growth and metastatic spread. Therefore, the in vivo analysis of blood-specific light traces could help identifying oral potentially malignant disorders or even overt malignant conditions at the periphery of the resected tumor. Furthermore, several studies have demonstrated that microvessel density (MD) assessed by histological and immunohistochemical analysis can be employed as a prognostic biomarker for OSCC [11-13].

Our work aims to evaluate the potential surgical benefits of mucosal margin assessment for OSCC using a platform which integrates intraoperative MM and NBI.

\section{Methods}

\section{Patients and tissue specimens}

This pilot prospective non-randomized study was approved by the local ethics committee (approval \#19_2018bis). A total of 16 patients (10 males, 6 females) with OSCC eligible for surgical treatment were enrolled. Informed consent was obtained from all patients. Only patients diagnosed and managed in IRCCS $\mathrm{Ca}^{\prime}$ Granda Foundation - Policlinico Maggiore Hospital, Milan, Italy, > 18 years old, chemotherapy- and radiotherapy-naïve, with no history of cancer were included. All patients underwent surgical treatment with a program established according to the guidelines of the American Joint Committee on Cancer (7th edition) [2].

\section{Macroscopic and narrow band imaging surgical margins assessment in vivo}

The MM was assessed by a craniofacial surgeon at a distance of 1,5-2 cm from the tumor, as described (Fig. 1a) $[7,14]$. Subsequently, two ears, nose and throat (ENT) surgeons performed intraoperative NBI endoscopic evaluation using a scope of $4 \mathrm{~mm}$ outside diameter (Olympus Visera Pro system, Center Valley, PA America, with OTV-S7Pro camera and CLV-S40Pro light source). This intraoperative analysis allowed for the identification of the interface between the likely neoplastic/dysplastic and likely healthy areas, i.e. NBI margin. Next, the maxillofacial surgeon performed multiple biopsies of both the MM and the NBI margins. For each patient, from 2 to 6 bioptic samples were obtained. The NBI margins were then classified as overlapping, external, or internal, compared to the MM. In case of overlap between the MM and NBI margins, only one biopsy was performed (Fig. 1).

\section{Histopathological analysis and pathologic surgical margins assessment}

Hematoxylin and eosin (H\&E) stained frozen sections of the MM margins were intraoperatively analyzed by a pathologist as part of the standard protocol to drive the surgical intervention. All surgical samples, including the tumor, the MM and NBI margins, were then analyzed after tissue processing by two pathologists (NF and MM), as shown in Fig. 1a. Specifically, all cases were classified and graded following the latest World Health Organization criteria [15]. Pathologic staging was assessed according to the current TNM staging system [16]. The presence of tumor infiltrating lymphocytes (TILs) was assessed as described [17]. The MM and NBI surgical margins were defined as positive in the presence of OSCC and/or dysplasia; otherwise, they were marked as negative.

\section{Immunohistochemistry and microvessel density analysis}

MD was investigated by immunohistochemistry (IHC) in the MM and NBI surgical margins. Representative $4-\mu \mathrm{m}$-thick sections were cut from the MM, NBI, and tumor blocks and subjected to IHC using pre-diluted antibodies against CD34 as previously described [18]. Positive and negative controls were included in each slide run. Briefly, the protocols use an automated staining system (Dako Omnis) and anti-human prediluted antibodies [19]. Protein expression was analyzed in all different samples by two independent pathologists (NF and SF). Discordant results were resolved during dedicated consensus sessions. Sections were first observed at low magnification (40x) to identify the areas with the higher concentration of vessels. Then, the vessels count was performed at 200x by means of a customized digital image analysis algorithm using the Aperio CS2 instrument (Leica Microsystems Srl) [20]. The MD value was expressed as a percentage. Each CD34-positive structure (round, oval, and irregular) separated from other profiles or tissue elements was counted as a single vessel, regardless of the presence of a clear lumen.

\section{Statistical analysis}

Data were analyzed using Prism 4.0 (GraphPad Inc., La Jolla, CA, USA). Differences among sample groups were analyzed using the unpaired Student's t-test as previously described [21]. The association between positive margins was evaluated by Fisher's exact test according to the classification proposed by Piazza and collaborators [22]. Statistical significance was assumed for a probability value (p) less than 0.05 . 


\section{A}

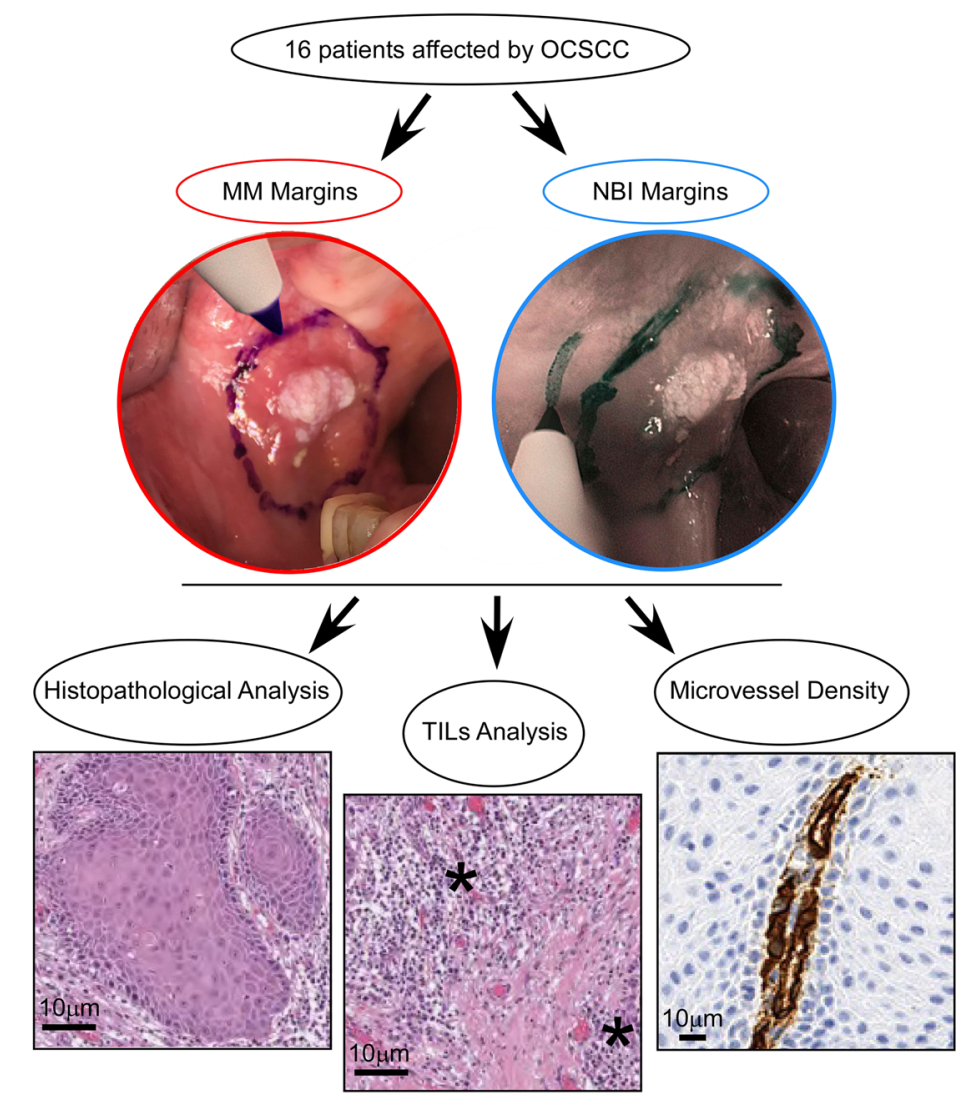

B
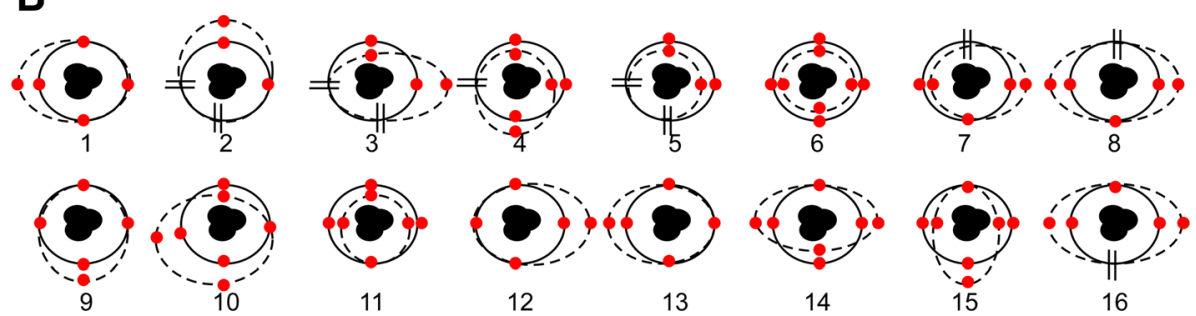

11

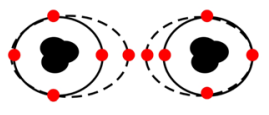

12

13
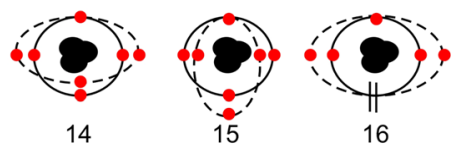

Tumor $\bigcirc \mathrm{MM}$ margin ؛́) NBI margin =NA • Biopsy

Fig. 1 a Schematic overview of the study. TILs are highlighted by stars. Original magnification of the micrographs 100X. b Schematic image of MM and NBI margins for the 16 OSCC patients. Red dots represent the cardinal points related to the biopsies performed for the excision of the mucosal margins

\section{Results}

Sixteen patients (10 males and 6 females) who underwent surgery for OSCC were included in this study (age 23 to 92 years old, mean 68 years). Tumor sites included the tongue $(n=6)$, lower alveolar ridge/mandible $(n=3)$, hard palate $(n=2)$, cheek $(n=2)$, floor of mouth $(n=2)$, and upper alveolar ridge/maxilla $(n=1)$. Clinicopathologic data are summarized in Table 1.

\section{Integration of $\mathrm{MM}$ and $\mathrm{NBI}$ margins is superior to $\mathrm{MM}$ and NBI alone}

Taken together, 104 specimens were analyzed, including 16 (15.4\%) tumors, 34 (32.7\%) MM, 34 (32.7\%) NBI margins, and 20 (19.2\%) MM-NBI overlapping margins (Fig. 1b). The NBI margins were closer to the lesion in 17 (50\%) cases (Fig. 1b) compared to the MM assessment. However, this method showed no propensity to allow for a more conservative resection, given that in the same number of margins $(n=17,50 \%)$ was the MM the more conservative approach. Furthermore, this heterogeneity was irrespective of the tumor site and was not present at a single-patient level. At the histological examination, the margins collected with the MM intraoperative assessment revealed dysplasia in $3(8.8 \%)$ cases and OSCC in 1 (2.9\%) case, while $30(88.2 \%)$ samples were negative as represented in Table 2 and Fig. 2a. The analysis of the NBI margins showed dysplasia and 
Table 1 Demographic and clinicopathologic features of the study group

\begin{tabular}{|c|c|}
\hline Features & Number of cases (\%) \\
\hline \multicolumn{2}{|l|}{ Sex } \\
\hline Male & $10(62.5)$ \\
\hline Female & $6(37.5)$ \\
\hline \multicolumn{2}{|l|}{ Age } \\
\hline Mean & 68.25 \\
\hline \multicolumn{2}{|l|}{ Smoking } \\
\hline Yes & $3(19)$ \\
\hline No & $4(25)$ \\
\hline Ex smoker & $9(56)$ \\
\hline \multicolumn{2}{|l|}{ Alcohol } \\
\hline Yes & $12(75)$ \\
\hline No & $3(19)$ \\
\hline Ex drinker & $1(6)$ \\
\hline \multicolumn{2}{|l|}{ Site } \\
\hline Tongue & $6(37.5)$ \\
\hline Mandible & $3(19)$ \\
\hline Palate & $2(12.5)$ \\
\hline Cheek & $2(12.5)$ \\
\hline Floor of the mouth & $2(12.5)$ \\
\hline Maxilla & $1(6)$ \\
\hline \multicolumn{2}{|l|}{ T Staging } \\
\hline $\mathrm{T} 1$ & $6(37.5)$ \\
\hline $\mathrm{T} 2$ & $5(31.25)$ \\
\hline T3 & $1(6.25)$ \\
\hline T4 & $4(25)$ \\
\hline \multicolumn{2}{|l|}{ N Staging } \\
\hline $\mathrm{Nx}$ & $3(18.75)$ \\
\hline NO & $7(43.75)$ \\
\hline N1 & $3(18.75)$ \\
\hline N2 & $3(18.75)$ \\
\hline \multicolumn{2}{|l|}{ Grading } \\
\hline G1 & $2(12.5)$ \\
\hline G2 & $13(76.4)$ \\
\hline G3 & $1(6.25)$ \\
\hline \multicolumn{2}{|l|}{ Vascular invasion } \\
\hline Yes & 0 \\
\hline No & $9(56.25)$ \\
\hline \multicolumn{2}{|l|}{ Perineural invasion } \\
\hline Yes & $5(31.25)$ \\
\hline No & $11(68.75)$ \\
\hline
\end{tabular}

OSCC in $2(5.9 \%)$ and 1 (2.9\%) cases; respectively, while 31 (91.2\%) margins were negative, as confirmed by histological examination (Table 2 and Fig. 2b). Among the 20 overlapping MM-NBI margins, 2 (10\%) cases were positive. In particular, positive margins showed a significant association with thick and thin nonkeratinized epithelial cells [23] $(p=0.027)$. These data suggest that the intraoperative integration of $M M$ and NBI analysis might allow for a more conservative excision of OSCC compared to each of the two methods alone.

High levels of microvessel density are related to positive mucosal margins irrespective of the method used for their assessment

MD has been investigated in 83 margins and matched OSCCs. This analysis showed significantly high CD34 levels in pathological margins compared to the normal ones $(p<0.0001$, Fig. $2 \mathrm{c})$. This observation was unrelated to the intraoperative method of surgical margins assessment (i.e. MM and NBI). Internal and external margins didn't show a statistically significant different MD, akin to the tumor site.

\section{Discussion}

The use of new technologies to investigate tumor behavior and microenvironment is of great interest in this era of precision medicine. Several studies unraveled the role of molecular biomarkers for the diagnostic and therapeutic process in patients with OSCC [24-26]. The application of "biologic endoscopy" to intraoperative surgical procedures represents another step forward towards the realization of the potentials of customized surgery $[9,10,27,28]$. Autofluorescence detection and NBI technology have already been tested in the definition of resection margins in OSCC and demonstrated to be reliable and cost-effective $[9,29]$. Poh et al. [29] described the ability of autofluorescence to identify malignant and pre-malignant lesions. Tirelli et al. [10] reported an overall diagnostic gain of $8.5 \%$ using NBI, allowing a better definition of the tumor extension. They observed adequate resection margins in $74.2 \%$ of cases. Moreover, a resection enlargement of $11 \pm 3 \mathrm{~mm}$ was performed consequently for intraoperative NBI evaluation [9], which revealed moderate dysplasia and cancer in 25 and $75 \%$ of samples respectively.

In this study, we performed a comparison between the mucosal margins assessment by $\mathrm{MM}$ and NBI, using their histological counterparts as "gold standard". Overall, we have observed that $50 \%$ of NBI margins were external or internal to the traditional surgical (i.e. $\mathrm{MM}$ ) ones. These results confirm previous observations that NBI margins are usually wider than MM margins [9]. Interestingly, we observed that in approximately $30 \%$ of cases the NBI technology coupled with traditional surgical assessment is able to reduce the extent of the resection, as confirmed by the histological analysis. 
Table 2 Demographic, clinicopathologic characteristics, and surgical margins status of the patients included in this study. NBI, narrow-band imaging; MM, macroscopic margin, AU, alcohol units; n.a., not available; RT, radiotherapy; CT, chemotherapy. When NBI and MM were overlapping, only one biopsy was performed

\begin{tabular}{|c|c|c|c|c|c|c|c|c|c|c|c|c|c|}
\hline Case & $\begin{array}{l}\text { Age } \\
\text { (range) }\end{array}$ & Smoking & Alcohol & Site & $\begin{array}{l}\text { Piazza et al. } \\
\text { Classification [23] }\end{array}$ & $\begin{array}{l}\text { Staging } \\
\text { TNM }\end{array}$ & Grading & $\begin{array}{l}\text { Lympho- } \\
\text { vascular/ } \\
\text { Perineural } \\
\text { invasion }\end{array}$ & $\begin{array}{l}\text { Sample } \\
1 \mathrm{NBI} / \\
\mathrm{MM}\end{array}$ & $\begin{array}{l}\text { Sample } \\
2 \mathrm{NBI} / \\
\text { MM }\end{array}$ & $\begin{array}{l}\text { Sample } \\
3 \mathrm{NBI} / \\
\mathrm{MM}\end{array}$ & $\begin{array}{l}\text { Sample } \\
4 \mathrm{NBI} / \\
\mathrm{MM}\end{array}$ & $\begin{array}{l}\text { Adjuvant } \\
\text { Therapy }\end{array}$ \\
\hline 1 & $50-60$ & No & $\begin{array}{l}\text { Yes (2 } \\
\text { AU/die) }\end{array}$ & Lateral Tongue & $2 b$ & T1Nx & $\mathrm{G} 2$ & $\mathrm{No} / \mathrm{No}$ & - & $-1-$ & - & - & No \\
\hline 2 & $70-80$ & Ex & $\begin{array}{l}\text { Yes (2 } \\
\text { AU/die) }\end{array}$ & Floor of mouth & $2 a$ & T2 NO & G2 & No/Yes & $-/-$ & - & n.a. & n.a. & RT \\
\hline 3 & $50-60$ & Yes & $\begin{array}{l}\text { Yes (2 } \\
\text { AU/die) }\end{array}$ & Ventral Tongue & $2 a$ & T2 NO & G2 & No/Yes & $-1-$ & $-/-$ & n.a. & n.a. & RT \\
\hline 4 & $50-60$ & Ex & $\begin{array}{l}\text { Yes (1 } \\
\text { AU/die) }\end{array}$ & Floor of mouth & $2 a$ & $\mathrm{~T} 1(\mathrm{~m}) \mathrm{Nx}$ & n.a. & $\mathrm{No} / \mathrm{No}$ & $+/-$ & $-/-$ & $-1-$ & n.a. & $C T+R T$ \\
\hline 5 & $50-60$ & Ex & $\begin{array}{l}\text { Yes (1 } \\
\text { AU/die) }\end{array}$ & $\begin{array}{l}\text { Maxilla/Alveolar } \\
\text { Mucosa }\end{array}$ & 1 & $\mathrm{~T} 4 \mathrm{aNx}$ & G1 & No/No & $-/-$ & $-/-$ & n.a. & n.a. & No \\
\hline 6 & $>80$ & No & $\begin{array}{l}\text { Yes (1 } \\
\text { AU/die) }\end{array}$ & $\begin{array}{l}\text { Mandible/ } \\
\text { Alveolar Mucosa }\end{array}$ & 1 & T4aNO & G1 & No/No & $-1-$ & $-/-$ & $-/-$ & $-/-$ & No \\
\hline 7 & $60-70$ & Ex & $\begin{array}{l}\text { Yes (1 } \\
\text { AU/die) }\end{array}$ & Lateral Tongue & $2 b$ & $\begin{array}{l}\text { T1 N1(E- } \\
\text { )R1 }\end{array}$ & G2 & No/No & n.a. & $-/-$ & - & $-/+$ & $C T+R T$ \\
\hline 8 & $>80$ & No & No & Cheek & $2 b$ & T2N1R0 & G2 & No/Yes & n.a. & $-/+$ & $-1-$ & - & No \\
\hline 9 & $>80$ & No & $\begin{array}{l}\text { Ex } \\
\text { Drinker }\end{array}$ & Hard Palate & 1 & $\begin{array}{l}\text { T4aN2b } \\
\text { (E-) RO }\end{array}$ & $\mathrm{G} 2$ & No/No & - & - & - & $-/-$ & No \\
\hline 10 & $70-80$ & Ex & No & $\begin{array}{l}\text { Mandible/ } \\
\text { Retromolar } \\
\text { Trigone }\end{array}$ & $2 b$ & $\begin{array}{l}\text { T2 N1 } \\
\text { (E-) R0 }\end{array}$ & G3 & $\mathrm{No} / \mathrm{No}$ & $+/-$ & - & $-1-$ & $-/-$ & RT \\
\hline 11 & $<30$ & Ex & $\begin{array}{l}\text { Yes (1 } \\
\text { AU/die) }\end{array}$ & Lateral Tongue & $2 b$ & $\mathrm{~T} 2 \mathrm{~N} 2 \mathrm{~b}$ & G2 & No/Yes & $+/+$ & $-/-$ & + & $-/-$ & $C T+R T$ \\
\hline 12 & $60-70$ & Ex & $\begin{array}{l}\text { Yes (1 } \\
\text { AU/die) }\end{array}$ & $\begin{array}{l}\text { Mandible/ } \\
\text { Alveolar Mucosa }\end{array}$ & 1 & T2 NORO & G2 & No/Yes & - & $-/-$ & - & - & No \\
\hline 13 & $>80$ & Yes & No & Lateral Tongue & $2 b$ & T1N2b & G2 & No/No & - & - & - & $-/+$ & No \\
\hline 14 & $>80$ & Ex & $\begin{array}{l}\text { Yes (1 } \\
\text { AU/die) }\end{array}$ & Cheek & $2 b$ & T1 NO & G2 & No/No & + & $-/-$ & $-/-$ & $-/-$ & No \\
\hline 15 & $70-80$ & Ex & $\begin{array}{l}\text { Yes (1 } \\
\text { AU/die) }\end{array}$ & Hard Palate & 1 & T4aNO & G2 & No/No & - & $-/-$ & $-1-$ & $-/-$ & No \\
\hline 16 & $50-60$ & Yes & $\begin{array}{l}\text { Yes (1 } \\
\text { AU/die) }\end{array}$ & Floor of mouth & $2 a$ & T1 NO & G2 & No/No & - & $-/-$ & n.a. & $-/-$ & No \\
\hline
\end{tabular}

Moreover, NBI and MM specimens revealed 2 and 3 mild dysplasia, respectively. In particular, positive margins were significantly localized in thick and thin non-keratinized epithelia with a low papillary density [23]. These data confirm the safety of the NBI technique and provide previously unavailable data that the integration of MM and NBI margins is superior to MM and NBI alone in OSCC surgical management [23, 30].

There are several lines of evidence that the activation of neoangiogenesis pathways represents a founder molecular event in OSCC initiation and progression [31]. Previous studies have demonstrated that high levels of MD are associated with a more aggressive clinical course in head and neck cancers [31-35]. In the present study, MD was quantified by the measurement of the areas lined by elements expressing CD34, which is a transmembrane protein encoded by the homonymous gene located at chromosome 1q. Taken together, we detected significant higher levels of $\mathrm{MD}$ in the positive margins compared to the normal mucosa. In several solid tumors, neoangiogenesis carries heavy traffic of non-malignant cells, especially $\mathrm{B}$ and $\mathrm{T}$ lymphocytes. These data confirm crucial role of the immune surveillance in head and neck cancer $[36,37]$.

Here, we evaluated the surgical margins status in OSCC by means of NBI endoscopy and the pathological identification of neoangiogenesis and intratumor immune response. This pilot study highlights that the surgical and NBI margins are comparable in terms of reliability. This notion, however, should be considered in the context of the small sample size investigated in the present work. An intrinsic limitation of this study is represented by absence of deep margin assessment, given that the NBI technology allows only for the evaluation of the perimetral margins. Further prospective studies 

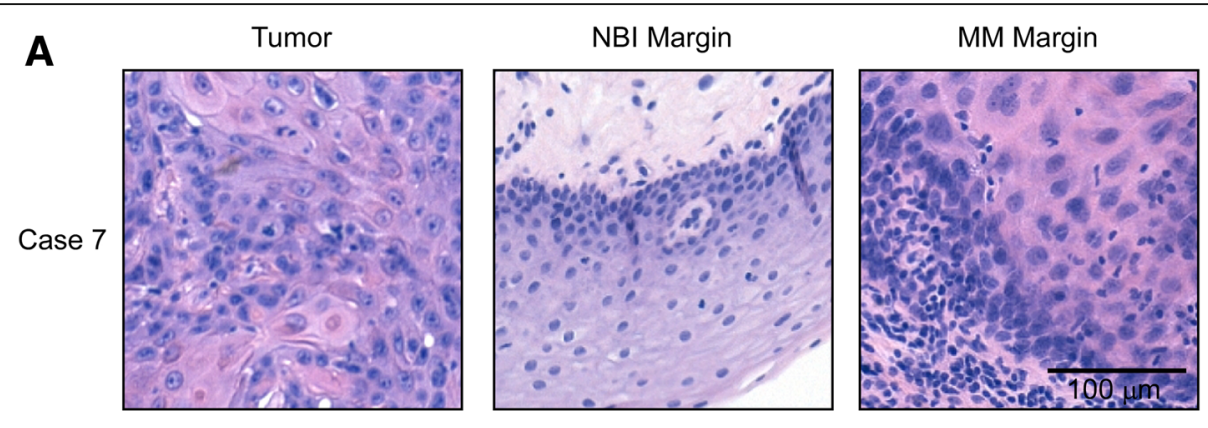

\section{B}
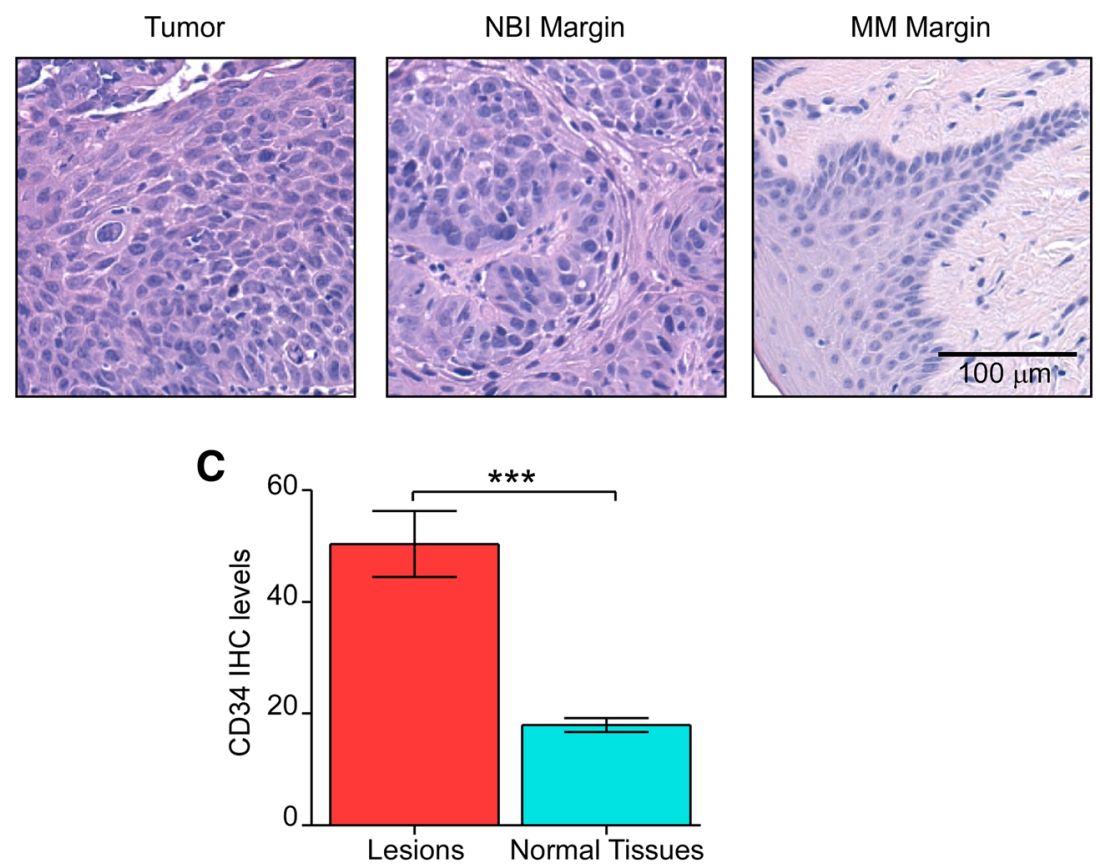

Fig. 2 a Representative histological micrographs of the primary tumor, NBI and MM margins in a case (\#7) where NBI margins are negative and a MM shows low-grade dysplasia. b Representative histological micrographs of the primary tumor, NBI and MM margins in a case (\#4) were an NBI margin is positive for high-grade dysplasia, while MM are negative. Original magnification is 100X. c CD34 protein levels in positive (red) and negative (cyan) margins. $p<0.0001$ by unpaired Student's t-test

embracing larger cohorts of patients are warranted to define the operational implications of our observations. This would lead to standardized intraoperative employment of this novel integrated strategy.

\section{Conclusion}

The integration of the traditional MM assessment with the NBI technology can allow for more conservative surgical interventions in OSCC.

\section{Abbreviations}

ENE: Extranodal extension; ENT: Ears, nose and throat; H\&E: Hematoxylin and eosin; IHC: Immunohistochemistry; MD: Microvessel density; MM: Macroscopic margins; NBI: Narrow band imaging; OSCC: Oral squamous cell carcinoma; TILs: Tumor infiltrating lymphocytes

\section{Acknowledgments}

The Authors would like to thank Prof. Alto Gianni', Prof. Stefano Ferrero, and Prof. Lorenzo Pignataro for fostering this study.

\section{Funding}

Not applicable.

\section{Availability of data and materials}

The dataset used and analysed during the present study is available from the corresponding author upon reasonable request.

\section{Authors' contributions}

Study concept, design, and supervision by ABa and NF. Acquisition, analysis, and interpretation of data: $A B, N F, A B a, D C$, and $C M$. $A B O, D C, C M$ and $L B$ reviewed the clinical records. Clinicopathologic correlations were performed by $A B a, N F$, and $P C$, with the substantial contribution of $A B o$ and $A F$. Initial histologic review of the cases was performed by NF and MM. The statistical analysis was carried out by NF and AF. Iconography and image processing by $C M, A F$, and NF. CM wrote the first draft of the manuscript, which was initially reviewed by Aba, AF, and NF. Subsequently, all authors edited and approved the final draft.

\section{Ethics approval and consent to participate}

The study was approved by the ethics committee of the Fondazione IRCCS Ca' Granda under the vote \#19_2018bis. All participants signed informed consent forms. 


\section{Consent for publication}

Not applicable.

\section{Competing interests}

The authors declare that they have no competing interests.

\section{Publisher's Note}

Springer Nature remains neutral with regard to jurisdictional claims in published maps and institutional affiliations.

\section{Author details}

${ }^{1}$ Department of Biomedical, Surgical, and Dental Sciences, University of Milan, Fondazione IRCCS Ca' Granda Policlinico, via Francesco Sforza, 35, 20122 Milan, Italy. ${ }^{2}$ Maxillo-Facial Surgery and Odontostomatology Unit, Fondazione IRCCS Ca' Granda Ospedale Maggiore Policlinico, Milan, Italy. 'Division of Pathology, Fondazione IRCCS Ca' Granda Ospedale Maggiore Policlinico, Milan, Italy. ${ }^{4}$ Otolaryngology Unit, Fondazione IRCCS Ca' Granda Ospedale Maggiore Policlinico, Milan, Italy.

\section{Received: 4 January 2019 Accepted: 23 April 2019}

\section{Published online: 17 May 2019}

\section{References}

1. Marur S, Forastiere AA. Head and neck squamous cell carcinoma: update on epidemiology, diagnosis, and treatment. Mayo Clin Proc. 2016;91(3):386-96.

2. Edge SB, Compton CC. The American joint committee on Cancer: the 7th edition of the AJCC cancer staging manual and the future of TNM. Ann Surg Oncol. 2010;17(6):1471-4.

3. Garavello W, Bertuccio P, Levi F, et al. The oral cancer epidemic in central and eastern Europe. Int J Cancer. 2010;127(1):160-71.

4. Adelstein D, Gillison ML, Pfister DG, et al. NCCN guidelines insights: head and neck cancers, version 2. J Natl Compr Canc Netw. 2017;15(6):761-70

5. Shah AK. Postoperative pathologic assessment of surgical margins in oral cancer: a contemporary review. J Oral Maxillofac Pathol. 2018;22(1):78-85.

6. Loree TR, Strong EW. Significance of positive margins in oral cavity squamous carcinoma. Am J Surg. 1990;160(4):410-4.

7. Hinni ML, Ferlito A, Brandwein-Gensler MS, et al. Surgical margins in head and neck cancer: a contemporary review. Head Neck. 2013;35(9):1362-70.

8. Tirelli G, Zacchigna S, Boscolo Nata F, Quatela E, Di Lenarda R, Piovesana M. Will the mininvasive approach challenge the old paradigms in oral cancer surgery? Eur Arch Otorhinolaryngol. 2017;274(3):1279-89.

9. Tirelli G, Piovesana M, Gatto A, Tofanelli M, Biasotto M, Boscolo Nata F. Narrow band imaging in the intra-operative definition of resection margins in oral cavity and oropharyngeal cancer. Oral Oncol. 2015:51(10):908-13.

10. Tirelli G, Piovesana M, Gatto A, Torelli L, Di Lenarda R, Boscolo Nata F. NBI utility in the pre-operative and intra-operative assessment of oral cavity and oropharyngeal carcinoma. Am J Otolaryngol. 2017;38(1):65-71.

11. Jalayer Naderi N, Tirgari F, Keshavarz Z. Vascular endothelial growth factor expression and vascular density in oral squamous cell carcinoma (OSCC): a study on clinical and histopathologic significance. Med J Islam Repub Iran. 2016 Apr 18:30:358.

12. Weidner N, Semple JP, Welch WR, Folkman J. Tumor angiogenesis and metastasis--correlation in invasive breast carcinoma. N Engl J Med. 1991; 324(1):1-8.

13. Ingaleshwar PS, Pandit S, Desai D, Redder CP, Shetty AS, Mithun KM Immunohistochemical analysis of angiogenesis by CD34 and mast cells by toluidine blue in different grades of oral squamous cell carcinoma. J Oral Maxillofac Pathol. 2016;20(3):467-73

14. Williams MD. Determining adequate margins in head and neck cancers: practice and continued challenges. Curr Oncol Rep. 2016;18(9):54.

15. General Assembly of the World Medical Association. World medical association declaration of Helsinki: ethical principles for medical research involving human subjects. J Am Coll Dent. 2014 Summer;81(3):14-8.

16. Amin MB, Edge SB, Greene FL, et al. AJCC Cancer staging manual. Eighth ed. New York, NY: Springer; 2017.

17. Klauschen F, Müller KR, Binder A, et al. International scoring of tumorinfiltrating lymphocytes: from visual estimation to machine learning. Semin Cancer Biol. 2018:52(Pt 2):151-157.

18. Ercoli G, Lopez G, Ciapponi C, et al. Building Up a High-throughput Screening Platform to Assess the Heterogeneity of HER2 Gene Amplification in Breast Cancers. J Vis Exp. 2017;5(130).
19. Sciarra A, Lopez G, Corti C, et al. Columnar cell lesion and apocrine hyperplasia of the breast: is there a common origin? The role of prolactininduced protein. Appl Immunohistochem Mol Morphol. 2017 Oct 27.

20. Fusco N, Guerini-Rocco E, Del Gobbo A, et al. The contrasting role of p16Ink4A patterns of expression in neuroendocrine and nonneuroendocrine lung tumors: a comprehensive analysis with Clinicopathologic and molecular correlations. PLoS One. 2015;10(12): e0144923.

21. Fusco N, Lopez G, Corti C, et al. Mismatch repair protein loss as a prognostic and predictive biomarker regardless of microsatellite instability. JNCI Cancer Spectrum. 2018 Nov;4(2):pky056.

22. Szafarowski T, Sierdzinski J, Szczepanski MJ, Whiteside TL, Ludwig N, Krzeski A. Microvessel density in head and neck squamous cell carcinoma. Eur Arch Otorhinolaryngol. 2018;275(7):1845-51.

23. Piazza C, Del Bon F, Paderno A, et al. The diagnostic value of narrow band imaging in different oral and oropharyngeal subsites. Eur Arch Otorhinolaryngol. 2016;273(10):3347-53.

24. Irimie Al, Braicu C, Cojocneanu-Petric R, Berindan-Neagoe I, Campian RS Novel technologies for oral squamous carcinoma biomarkers in diagnostics and prognostics. Acta Odontol Scand. 2015;73(3):161-8.

25. Retzbach EP, Sheehan SA, Nevel EM, et al. Podoplanin emerges as a functionally relevant oral cancer biomarker and therapeutic target. Oral Oncol. 2018;78:126-36

26. Song W, Sun Y, Lin J, Bi X. Current research on head and neck cancerassociated long noncoding RNAs. Oncotarget. 2017;9(1):1403-25.

27. Sinha P, Bahadur S, Thakar A, et al. Significance of promoter hypermethylation of p16 gene for margin assessment in carcinoma tongue. Head Neck. 2009;31(11):1423-30.

28. Tirelli G, Piovesana M, Marcuzzo AV, et al. Tailored resections in oral and oropharyngeal cancer using narrow band imaging. Am J Otolaryngol. 2018;39(2):197-203.

29. Poh CF, Zhang L, Anderson DW, et al. Fluorescence visualization detection of field alterations in tumor margins of oral cancer patients. Clin Cancer Res. 2006;12(22):6716-22

30. Tirelli G, Piovesana M, Gatto A, Torelli L, Boscolo Nata F. Is NBI-guided resection a breakthrough for achieving adequate resection margins in Oral and oropharyngeal squamous cell carcinoma? Ann Otol Rhinol Laryngol. 2016;125(7):596-601.

31. Naderi NJ, Tirgari F, Keshavarz Z. Vascular endothelial growth factor expression and vascular density in oral squamous cell carcinoma (OSCC): a study on clinical and histopathologic significance. Med J Islam Repub Iran. 2016:30(1):1-6.

32. Albo D, Granick M, Jhala N, Atkinson B, Solomon MP. The relationship of angiogenesis to biological activity in human squamous cell carcinomas of the head and neck. Ann Plast Surg. 1994;32(6):588-94.

33. Ascani G, Balercia P, Messi M. Lupi et al. Angiogenesis in oral squamous cell carcinoma. Acta Otorhinolaryngol Ital. 2005;25(1):13-7.

34. Shivamallappa SM, Venkatraman NT, Shreedhar B, Mohanty L, Shenoy S. Role of angiogenesis in oral squamous cell carcinoma development and metastasis: an immunohistochemical study. Int J Oral Sci. 2011;3(4):216-24.

35. Li SH, Hung PH, Chou KC, Hsieh SHSY. Tumor angiogenesis in oral squamous cell carcinomas: the significance of endothelial markers and hotspot selection. J Med Sci. 2009;29:67-74

36. Lei $Y$, Xie Y, Tan YS, et al. Telltale tumor infiltrating lymphocytes (TIL) in oral, head \& neck cancer. Oral Oncol. 2016:61:159-65.

37. Wolf GT, Chepeha DB, Bellile E, Nguyen A, Thomas D, McHugh J. University of Michigan head and neck SPORE program. Tumor infiltrating lymphocytes (TIL) and prognosis in oral cavity squamous carcinoma: a preliminary study. Oral Oncol. 2015:51(1):90-5. 